\title{
Effects of SiC Particle Concentration on the Ultrasonic-Assisted Jet Electrodeposited Ni-SiC Nanocoatings
}

\author{
Mengyu Cao, Yuhang Yue, Xue Guo ${ }^{*}$ Baojing Wang* \\ College of Mechanical Science and Engineering, Northeast Petroleum University, Daqing 163318, \\ China \\ *E-mail: baojwang1234@,163.com
}

Received: 28 September 2021 / Accepted: 2 November 2021 / Published: 6 December 2021

\begin{abstract}
We demonstrate here the use of ultrasonic-assisted jet electrodeposition to prepare abrasive resistant coatings of Ni-SiC on Q235 steel substrate surface. We show that SiC nanoparticle concentration has a profound effect on the morphology and performance of deposited Ni-SiC nanocoatings. We perform a series of physico-chemical characterizations to reveal their structure and morphology to better optimize their abrasion resistance. We show that the $\mathrm{SiC}$ contents in the coatings increased first and then decreased as the $\mathrm{SiC}$ concentration increased. The ultrasonic-assisted jet deposited $\mathrm{Ni}-\mathrm{SiC}$ nanocoatings at $7 \mathrm{~g} / \mathrm{L}$ showed fine grains, smooth and compact microstructure surface, maximum composite amount of SiC nanoparticles, uniform distribution, and no obvious agglomeration. These features results in coatings which possess high microhardness, corrosion resistance and abrasive resistance at the same time.
\end{abstract}

Keywords: ultrasonic-assisted jet electrodeposition; Ni-SiC nanocoatings; SiC concentration; abrasive resistance; corrosion resistance

\section{FULL TEXT}

(C) 2022 The Authors. Published by ESG (www.electrochemsci.org). This article is an open access article distributed under the terms and conditions of the Creative Commons Attribution license (http://creativecommons.org/licenses/by/4.0/). 